\title{
Student understanding of period in introductory and quantum physics courses
}

\author{
Tong Wan ${ }^{1}$, Paul J. Emigh ${ }^{1}$, Gina Passante ${ }^{2}$, and Peter S. Shaffer ${ }^{1}$ \\ ${ }^{1}$ Department of Physics, University of Washington, Seattle, WA 98195-1560 \\ ${ }^{2}$ Department of Physics, California State University, Fullerton, CA 92834-6900
}

\begin{abstract}
Time dependence is an important concept in quantum mechanics that has been shown to be difficult for many students. In trying to understand the problems that students encounter, the Physics Education Group at the University of Washington is examining student ability to reason about the period of quantum states. As part of this investigation, we have begun to probe student understanding of period in other contexts (e.g., phasors and circular motion). Results from analogous written tasks administered in introductory and sophomore-level courses reveal related difficulties. The findings have implications for instruction and are guiding the design of curriculum (Tutorials in Physics: Quantum Mechanics) that is intended to improve student understanding of time dependence in quantum mechanics.
\end{abstract}

\section{INTRODUCTION}

Time dependence is a fundamental concept in quantum mechanics. Prior research suggests that students have difficulty in understanding the time evolution of basic quantities, such as wave functions, probabilities, and expectation values [1-3]. However, there has been little research on student ability to determine and interpret the underlying concept of period as applied to quantum states.

The time-dependent phase factors that determine the periods of quantum states are complex-valued functions derived from the Schrödinger equation. In this study, we initially designed questions to probe the ability of sophomore-level students to determine the periods of such functions and to interpret periods in the complex plane. Based on the findings, we designed analogous questions for introductory students in the contexts of phasors and circular motion. Although prior research has documented student difficulties with phasors [4] and rotational kinematics [5], the goal of this study is to identify patterns in student reasoning about period that are common across different courses and contexts. The results have implications for the development of curriculum to improve student understanding of time dependence in quantum mechanics.

\section{CONTEXT FOR RESEARCH}

This investigation has been carried out in three courses at the University of Washington: (1) a sophomore-level quantum mechanics course, (2) an introductory optics course, and (3) an introductory mechanics course. The quantum course covers the first five chapters of McIntyre's Quantum Mechanics: A Paradigms Approach [6]. It has three 50-minute lectures each week that use interactive methods such as clickers and worksheets from Tutorials in Physics: Quantum Mechanics [7]. A math methods course that covers complex-valued functions is a prerequisite. The introductory mechanics and optics courses both use Tipler and Mosca [8]. Each course has three 50-minute lectures, a 50-minute small-group section using Tutorials in Introductory Physics [9], and a 110-minute lab each week.

\section{STUDENT UNDERSTANDING IN QUANTUM COURSE (COMPLEX EXPONENTIALS)}

In order to probe student reasoning about the period of quantum states, we designed a set of questions in the context of complex-valued functions. These were given in an online survey in a sophomore-level quantum course after lecture instruction on the Schrödinger equation and time evolution, but before relevant research-based worksheets (tutorials) were given. The responses were not graded, but students were awarded participation credit. Figure 1 shows an abbreviated version of the multiple-choice questions. Students were not asked for explanations. Out of 118 students enrolled, 92 completed the survey.

The period in question A1 can be determined from its definition (e.g., using the equation $f(T)=f(0)$ given in the problem statement). Since $f(0)=1$ and the next time this function is equal to 1 is when the angle is equal to $2 \pi$, the period must satisfy the equation $\omega T / 2=2 \pi$. Thus $T=4 \pi / \omega$. Student performance is given in Table I.

About half of the students did not find the period correctly. The incorrect answers had been selected to probe potential confusion between period and other quantities. For example, option $\mathrm{C}$ was intended for students who

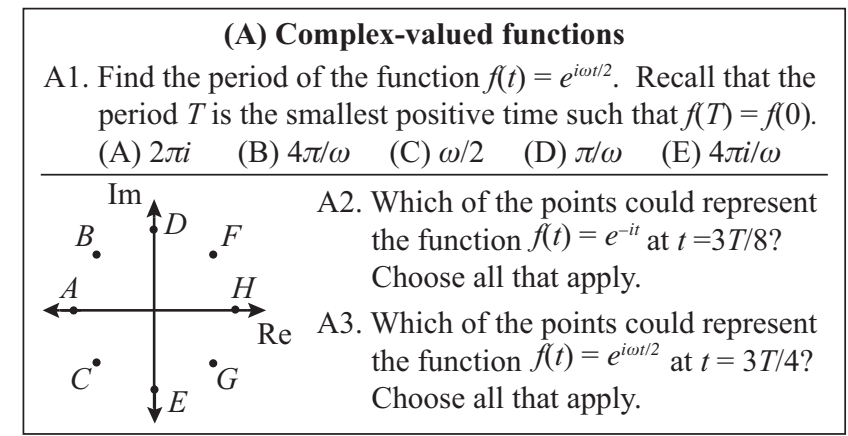

FIG. 1. Questions about the period of complex-valued functions given in a sophomore-level quantum course. 
Table I. Percentage of students choosing each answer in question A1. The correct answer is bolded.

\begin{tabular}{|c|c|c|c|c|c|}
\hline $\begin{array}{c}\mathrm{A} \\
(2 \pi i)\end{array}$ & $\begin{array}{c}\text { B } \\
(4 \pi / \omega)\end{array}$ & $\begin{array}{c}\mathrm{C} \\
(\omega / 2)\end{array}$ & $\begin{array}{c}\mathrm{D} \\
(\pi / \omega)\end{array}$ & $\begin{array}{c}\mathrm{E} \\
(4 \pi i / \omega)\end{array}$ & None \\
\hline $11 \%$ & $47 \%$ & $21 \%$ & $11 \%$ & $7 \%$ & $3 \%$ \\
\hline
\end{tabular}

confuse angular speed with period, option A for those who confuse angular displacement with period, and option D for students who incorrectly reason that period is halved when angular speed is halved.

Questions A2 and A3 probe student ability to relate the period of a complex-valued function to the complex plane. Question A3, in particular, focuses on when changes are made to both the magnitude and the direction of angular velocity. To answer, students can determine the initial value $(t=0)$ of the function in the complex plane (point $\mathrm{H}$ ); the direction in which the function progresses in the complex plane (clockwise and counter-clockwise, respectively); and the angular displacement over the given fraction of the period ( $3 / 8$ and $3 / 4$, respectively).

The results from questions $\mathrm{A} 2$ and $\mathrm{A} 3$ are given in Tables II and III, respectively. The rightmost columns of Table II show the initial position and the direction of motion that students most likely used to arrive at each common answer. Table III includes the most likely initial position, direction of motion, and angular displacement used by the students. Responses below 5\% are not shown.

About $35 \%$ of the students chose more than one answer in either question and included at least one of the answers shown in the tables. Though these answers fall below 5\%, it is worthwhile to include them in the analysis. We assume that the answers shown in the table would be more common if we do not allow multiple answers. The tendency to choose multiple answers may have been due to the presence of the phrase "choose all that apply" in the problem statement. However, it suggests that many students do not understand that complex-valued functions are single-valued.

Only about one-quarter of the students answered question A2 correctly. All of the responses above 5\% correspond to the points on the diagonals. This result

Table II. Percentage of the students choosing each answer in question A2. The correct answer is bolded.

\begin{tabular}{c|c|c}
\hline \hline Answer & Initial position & Direction of motion \\
\hline $\begin{array}{c}\mathbf{C} \\
(\mathbf{2 6 \%})\end{array}$ & Point H & Clockwise \\
\hline $\begin{array}{c}\mathrm{B} \\
(14 \%)\end{array}$ & Point H & Counter-clockwise \\
\hline $\begin{array}{c}\mathrm{G} \\
(9 \%)\end{array}$ & Point A & Counter-clockwise \\
\hline $\begin{array}{c}\mathrm{F} \\
(5 \%)\end{array}$ & Point A & Clockwise \\
\hline $\begin{array}{c}\mathrm{B}, \mathrm{C}, \mathrm{F} \mathrm{\&} \mathrm{G} \\
(5 \%)\end{array}$ & Point H and/or A & $\begin{array}{c}\text { Clockwise and/or } \\
\text { Counter-clockwise }\end{array}$ \\
\hline \hline
\end{tabular}

suggests that those students understand that $3 / 8$ of the period corresponds to $3 / 8$ of the circle. However, many of these students incorrectly determined the initial position of the function or the direction in which the function progresses in the complex plane. For example, point B corresponds to students who correctly determined the initial position (point $\mathrm{H}$ ) but incorrectly thought the function progresses counter-clockwise; points $\mathrm{F}$ and $\mathrm{G}$ correspond to students who incorrectly treated the function as starting at point $\mathrm{A}$ and progresses clockwise or counter-clockwise, respectively. Students who thought that the function could start at either point $\mathrm{H}$ or $\mathrm{A}$ and move in either direction would have chosen all of B, C, F \& G.

Students performed less well on question A3 than on A2. Only three answers were chosen by more than $10 \%$ of the students. This result suggests that many students have difficulty in interpreting the period in the complex plane when both the magnitude and direction of the angular velocity are changed.

The most common incorrect answer was point B (11\%). Most of these students had previously chosen either $\mathrm{B}$ or $\mathrm{C}$ in response to question $\mathrm{A} 2$, each of which is $3 / 8$ of a full circle from the correct starting point $H$. Thus, their reasoning may be based on a belief that the period is halved due to the factor, $1 / 2$, in the exponent.

Since the set of questions described above did not ask for student reasoning, we administered a very similar set in a subsequent offering of the same course. These students were asked to explain their reasoning in response to all three questions. Then we analyzed theses responses to identify the underlying line(s) of reasoning used by each student. For each question, we found that students' explanations for both the correct and incorrect answers were consistent with the interpretations discussed above.

Table III. Percentage of students choosing each answer in question A3. The correct answer is bolded.

\begin{tabular}{c|c|c|c}
\hline \hline Answer & $\begin{array}{c}\text { Initial } \\
\text { position }\end{array}$ & $\begin{array}{c}\text { Direction of } \\
\text { motion }\end{array}$ & $\begin{array}{c}\text { Angular } \\
\text { displacement }\end{array}$ \\
\hline $\begin{array}{c}\mathbf{E} \\
(\mathbf{1 3 \%})\end{array}$ & Point H & $\begin{array}{c}\text { Counter- } \\
\text { clockwise }\end{array}$ & $\mathbf{3} / \mathbf{4}$ circle \\
\hline $\begin{array}{c}\text { B } \\
(11 \%)\end{array}$ & Point H & $\begin{array}{c}\text { Counter- } \\
\text { clockwise }\end{array}$ & $3 / 8$ circle \\
\hline $\begin{array}{c}\text { G } \\
(7 \%)\end{array}$ & Point A & $\begin{array}{c}\text { Counter- } \\
\text { clockwise }\end{array}$ & $3 / 8$ circle \\
\hline $\begin{array}{c}\text { D* } \\
(5 \%)\end{array}$ & Point & $\begin{array}{c}\text { Clockwise/ } \\
\text { Counter- } \\
\text { clockwise }\end{array}$ & $3 / 4$ circle \\
\hline $\begin{array}{c}\text { D \& E } \\
(5 \%)\end{array}$ & Point & $\begin{array}{c}\text { Clockwise/ } \\
\text { Counter- } \\
\text { clockwise }\end{array}$ & $3 / 4$ circle \\
\hline $\begin{array}{c}\text { Not enough } \\
\text { info (11\%) }\end{array}$ & N/A & N/A & N/A \\
\hline \hline
\end{tabular}

*For answers D and E, there are two lines of reasoning that students could use. For example, for answer D: (1) start at point $\mathrm{H}$ and move clockwise, or (2) start at point A and move counter-clockwise. 


\section{STUDENT UNDERSTANDING IN OPTICS COURSE (PHASORS)}

Difficulty in reasoning about the period of complexvalued functions was widespread among the sophomorelevel students. Many incorrectly determined the initial position, the direction of motion, or the angular displacement. In particular, students often had difficulty when both the magnitude and the direction of the angular velocity were changed. The results inspired us to probe the ability of introductory students to reason about period.

We designed a set of three questions (set B) analogous to those given in the quantum course, but in the context of phasors. The questions use sinusoidal functions, which we expected would be easier for students than complex-valued functions. The questions were administered online after lecture instruction on phasors in an introductory optics course. Students could specify more than one phasor in their answers. Explanations were required. Students received participation credit for answering. Of the 390 students enrolled, 237 answered.

On the first question (B1), students were asked to determine the period when the angular speed is represented by the same quantity $\omega / 2$ as had been used in the quantum course. In the next two questions, they were asked to locate the point representing the function in a plane after: $3 / 8$ of the period (B2) and $3 / 4$ of the period when both the magnitude and the direction of the angular velocity are changed (B3). Figure 2 shows an abbreviated version of these questions.

Student performance on question B1 is given in Table IV. Only one-quarter of the students gave the correct answer (B). About one-third of the students answered $2 \pi / \omega$ (E) and in their explanations, many students interpreted $\omega$ in $\omega t / 2$ as the angular frequency (ignoring the factor, 1/2). Some directly stated that $2 \pi / \omega$ is the definition of period. Answers $\mathrm{C}(\omega / 2)$ and $\mathrm{D}(\pi / \omega)$ were also common. Those who chose $\mathrm{C}$ explained that the coefficient in front of $t$ is the period. Those who chose $\mathrm{D}$ reasoned that the period is halved because the angular frequency is halved.

\section{(B) Phasors}

B1. What is the period of the EM wave $\vec{E}=E_{o} \sin (k z+\omega t / 2) \hat{y}$ ?
(A) $2 \pi$
(B) $4 \pi / \omega$
(C) $\omega / 2$
(D) $\pi / \omega$
(E) $2 \pi / \omega$

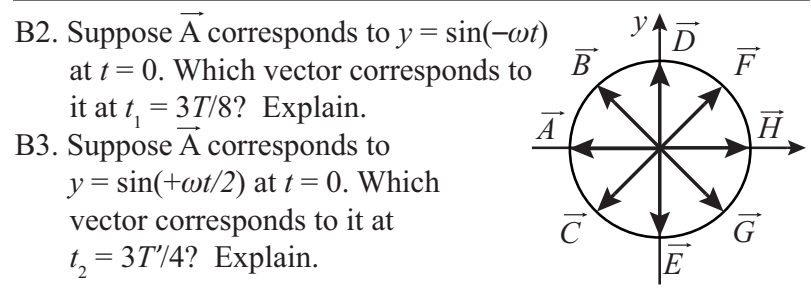

FIG. 2. Questions about period in the contexts of phasors given in an introductory optics course.
Table IV. Percentage of the students choosing each answer in question B1. The correct answer is bolded.

\begin{tabular}{c|c|c|c|c|c}
\hline \hline $\begin{array}{c}\mathrm{A} \\
(2 \pi)\end{array}$ & $\begin{array}{c}\mathrm{B} \\
(\mathbf{4} \boldsymbol{\pi} / \boldsymbol{\omega})\end{array}$ & $\begin{array}{c}\mathrm{C} \\
(\omega / 2)\end{array}$ & $\begin{array}{c}\mathrm{D} \\
(\pi / \omega)\end{array}$ & $\begin{array}{c}\mathrm{E} \\
(2 \pi / \omega)\end{array}$ & None \\
\hline $9 \%$ & $\mathbf{2 5 \%}$ & $14 \%$ & $13 \%$ & $36 \%$ & $3 \%$ \\
\hline \hline
\end{tabular}

On question $\mathrm{A} 1$, given in the quantum course, $\omega / 2$ and $\pi / \omega$ were also common incorrect answers. Thus, across the different contexts, it seems that many students confuse angular speed with period and do not understand how to interpret the factor, $1 / 2$, in $\omega t / 2$.

The second column of Table $\mathrm{V}$ shows student performance on question B2. For comparison, the first column shows the results from question A2 that correspond to each common line of reasoning for question $\mathrm{B} 2$.

As was the case for question A2, the most common answers for question B2 are the points on the diagonals. This result suggests that many of the students were able to relate the period of the phasor to the diagram, especially since they often stated that the phasor would rotate through $3 / 8$ of the circle. It also suggests that many of the sophomore-level students were able to relate the complexvalued function to the complex plane since the common responses are the same for the different contexts.

Although the introductory students seemed to be able to interpret period, many did not correctly determine the initial position or the direction of motion. It seemed as if many thought it is a convention that phasors start in the positive $x$-direction and that counter-clockwise is associated with a positive argument in the sine function. For example, many of the students who chose B for question B2 explained that the phasor starts at a vector marked $\mathrm{H}$ and rotates counterclockwise. Students who chose F often explained that the phasor rotated clockwise because of the negative sign in the argument. This type of reasoning is consistent with the answers from the quantum course.

In question B3, both the magnitude and the direction of the angular velocity are changed. Student performance is shown in Table VI. To simplify a comparison with the corresponding question in the quantum course, the first column shows the results from question A3.

Table V. Percentage of students choosing each answer in questions $\mathrm{A} 2$ and $\mathrm{B} 2$.

\begin{tabular}{c|c|c|c}
\hline \hline $\begin{array}{c}\mathbf{A 2} \\
(\mathbf{N = 9 2})\end{array}$ & $\begin{array}{c}\mathbf{B 2} \\
(\mathbf{N = 2 3 7})\end{array}$ & $\begin{array}{c}\text { Initial } \\
\text { position }\end{array}$ & $\begin{array}{c}\text { Direction } \\
\text { of motion }\end{array}$ \\
\hline $\begin{array}{c}\mathrm{C} \\
(26 \%)\end{array}$ & $\begin{array}{c}\mathrm{G} \\
(27 \%)\end{array}$ & Correct & Correct \\
\hline $\begin{array}{c}\mathrm{B} \\
(14 \%)\end{array}$ & $\begin{array}{c}\mathrm{F} \\
(15 \%)\end{array}$ & Correct & Incorrect \\
\hline $\begin{array}{c}\mathrm{G} \\
(9 \%)\end{array}$ & $\begin{array}{c}\mathrm{B} \\
(20 \%)\end{array}$ & Incorrect & Incorrect \\
\hline $\begin{array}{c}\mathrm{F} \\
(5 \%)\end{array}$ & $\begin{array}{c}\mathrm{C} \\
(8 \%)\end{array}$ & Incorrect & Correct \\
\hline
\end{tabular}


Table VI. Percentage of students choosing each answer in questions A3 $(\mathrm{N}=92)$ and $\mathrm{B} 3(\mathrm{~N}=237)$.

\begin{tabular}{c|c|c|c|c}
\hline \hline $\mathbf{A 3}$ & $\mathbf{B 3}$ & $\begin{array}{c}\text { Initial } \\
\text { position }\end{array}$ & $\begin{array}{c}\text { Direction } \\
\text { of motion }\end{array}$ & $\begin{array}{c}\text { Angular } \\
\text { displace- } \\
\text { ment }\end{array}$ \\
\hline $\begin{array}{c}\mathrm{E} \\
(13 \%)\end{array}$ & $\mathrm{E}(25 \%)$ & Correct & Correct & Correct \\
\hline $\begin{array}{c}\mathrm{B} \\
(11 \%)\end{array}$ & $\mathrm{F}(8 \%)$ & Correct & Correct & Incorrect \\
\hline $\begin{array}{c}\mathrm{G} \\
(7 \%)\end{array}$ & $\mathrm{B}(12 \%)$ & Incorrect & Correct & Incorrect \\
\hline $\begin{array}{c}\mathrm{D} \\
(5 \%)\end{array}$ & $\begin{array}{c}\mathrm{D} * \\
(17 \%)\end{array}$ & $\begin{array}{c}\text { Correct/ } \\
\text { Incorrect }\end{array}$ & $\begin{array}{c}\text { Incorrect/ } \\
\text { Correct }\end{array}$ & Correct \\
\hline $\begin{array}{c}\mathrm{C} \\
(4 \%)\end{array}$ & $\begin{array}{c}\mathrm{G} \\
(14 \%)\end{array}$ & Correct & Incorrect & Incorrect \\
\hline \hline
\end{tabular}

*There are two common lines of reasoning that students used to arrive at answer D: (1) correct initial position and incorrect direction of motion, or (2) incorrect initial position and correct direction of motion.

Only one-quarter of the students answered question B3 correctly. Many of the students who chose D explained that the phasor rotates counter-clockwise starting at the vector marked A, which is consistent with the reasoning in question B2 that counter-clockwise is defined as the positive direction. We also found that some students incorrectly related angular speed to period, and reasoned incorrectly about period when angular velocity is halved. For example, some students who chose B or G explained that the period is halved due to the factor, $1 / 2$, and thus the phasor would go over the same angle as in B2 for the same time interval. This type of reasoning is consistent with student responses to question A3 in the quantum course.

\section{ADDITIONAL COMPARISON OF STUDENT PERFORMANCE FOR DIFFERENT CONTEXTS}

The results from the questions described thus far indicate that many students have difficulty in reasoning about period in the contexts of complex-valued functions and phasors. We were interested in whether similar difficulties would also be present in simpler contexts. We therefore designed a set of analogous questions based on uniform circular motion, which seems a less abstract context. These questions were administered on exams in introductory mechanics courses after lectures and labs on this topic.
Overall, student performance was about $20 \%$ to $30 \%$ better on each of the three questions about circular motion than on the analogous questions for phasors or complexvalued functions. The results are preliminary, since there are small differences between the questions that make a direct comparison difficult. However, the findings are encouraging, because they have implications for instruction and the development of curriculum to help students build a functional understanding of period that they can apply in the contexts of phasors and complex-valued functions.

\section{DISCUSSION}

We have identified patterns in student reasoning about periods of sinusoidal functions that are common across different courses and contexts. We have found that it is difficult for many students to determine and reason about period when angular speed is changed. Moreover, many students confuse period with angular speed or angular displacement. Others reason that the period is halved when angular speed is halved. Students also have difficulty in determining the initial values of sinusoidal functions and their direction of motion, regardless of the form (complex exponential or real sinusoidal).

Questions used in this research require similar reasoning independent of the context. The time dependence of complex-valued functions and phasors can be interpreted as uniform circular motion and represented both physically and mathematically. The results suggest that students perform much better on questions in the context of circular motion than either phasors or complex-valued functions. We believe that curriculum that uses uniform circular motion as a model for periodic time dependence could be designed to help students better interpret the time dependence of phasors, complex-valued functions, and quantum states. Further research will focus on the development and evaluation of such curriculum.

\section{ACKNOWLEDGMENTS}

We would like to thank UW faculty members R. Daryl Pedigo, Nikolai Tolich, Jens Gundlach, and James Reid for welcoming this research in their courses. This study is funded through NSF grant 1022449.

[7] L. C. McDermott et al, Tutorials in Physics: Quantum Mechanics, Preliminary edition (2016).

[8] P. A. Tipler \& G. Mosca, Physics for Scientists and Engineers, $6^{\text {th }}$ edition (2007).

[9] L. C. McDermott et al, Tutorials in Introductory Physics, Preliminary $2^{\text {nd }}$ edition (2011). 